\title{
Leflunomide-Induced Interstitial Lung Disease: A Case Report
}

\author{
Aygül Güzel ${ }^{1}$, Nurhan Köksal ${ }^{1}$, Ayşenur Gök ${ }^{1}$, Muzaffer Elmalı
}

${ }^{1}$ Department of Chest Diseases, Ondokuz Mayıs University Faculty of Medicine, Samsun

${ }^{2}$ Department of Radiodiagnostic, Ondokuz Mayıs University Faculty of Medicine, Samsun

\begin{abstract}
Leflunomide (LEF) induced interstitial pneumonitis is a very rare condition but potentially fatal. We report a case of LEF induced interstitial pneumonitis. A 63-year-old woman followed-up for 37 years with the diagnosis of rheumatoid arthritis treated with LEF (20 mg/day) since 5 months were admitted to our hospital with cough, dyspnea, fever, and dark sputum. Chest radiography represented bilateral alveolar consolidation. High-resolution computed tomography demonstrated diffuse ground-glass appearance and interlobular septal thickening. Since the patient's clinics and radiologic findings improved dramatically after the cessation of LEF and recieving oral steriod therapy, she was diagnosed as drug-induced interstitial lung disease. In conclusion, when nonspecific clinical signs such as respiratory distress, cough and fever seen during the use of LEF, drug-induced interstitial lung disease should be kept in mind for the differantial diagnosis.
\end{abstract}

Keywords: Adverse reaction, drug, interstitial lung disease, leflunomide

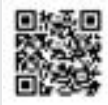

Received Date: 11.09 .2013

Accepted Date: 07.12.2013

Address for correspondence

Aygül Güzel, Department of Chest Diseases, Ondokuz Mayss University Faculty of Medicine, Samsun, Turkey

E-mail: aygul.guzel@yahoo.com

This work is licensed under a Creative Commons Attribution-NonCommercia 4.0 International License.

DOI: $10.5152 /$ ejp.2014.93357

-Available online at www.eurasianjpulmonol.com

\section{INTRODUCTION}

Interstitial lung disease (ILD) associated with drugs is a rare clinical condition. The clinical course can vary from benign lung infiltrations to mortal acute respiratory failure syndrome (1). In drug-induced ILDs, the causing mechanism has not been cleared yet. It is stated in the pathogenesis that lung cytotoxicity caused by drugs, immune response developing against drugs, and genetic predisposition have roles $(1,2)$.

Leflunomide (LEF) is an immunomodulator drug that plays a role in pyrimidine synthesis in $\mathrm{T}$ lymphocytes with its active metabolite $\mathrm{A} 771726$ and becomes effective by inhibiting the dihydroorotate dehydrogenase enzyme (2). It has been shown in studies that it reduces articulation symptoms in rheumatoid arthritis (RA) treatment and prevents progression (3). Side effects associated with LEF-induced hepatotoxicity, ulcer in the mouth, headache, hypertension, weight loss, hair loss, peripheral neural neuropathy, and ILD (4). The frequency of LEF-induced ILD varies between 0.08 and $0.49 \%$ and is seen rarely (5). In literature, there are cases frequently reported from Far East and rarely from Western countries (2). The number of case reports on this issue is quite low in our country (6).

In this case report, ILD due to LEF usage was discussed together with the literature, because it is a rare condition and especially, for the fact that this complication that may occur during LEF use.

\section{CASE PRESENTATION}

A 63-year-old female patient who had been followed up with RA diagnosis for 37 years was admitted to our clinic with complaints of cough, shortness of breath, fever, and thick phlegm. From her history, it was learned that the complaints started 10 days before the admission and they presented with a flu-like infection with cough, nasal flow, and sore throat. Fever, expectorating, and difficulty in breathing were added to these complaints later on. She received antibiotic (levofloxacin and ceftriaxone) treatment after being hospitalized in the health care institution where she was admitted because 


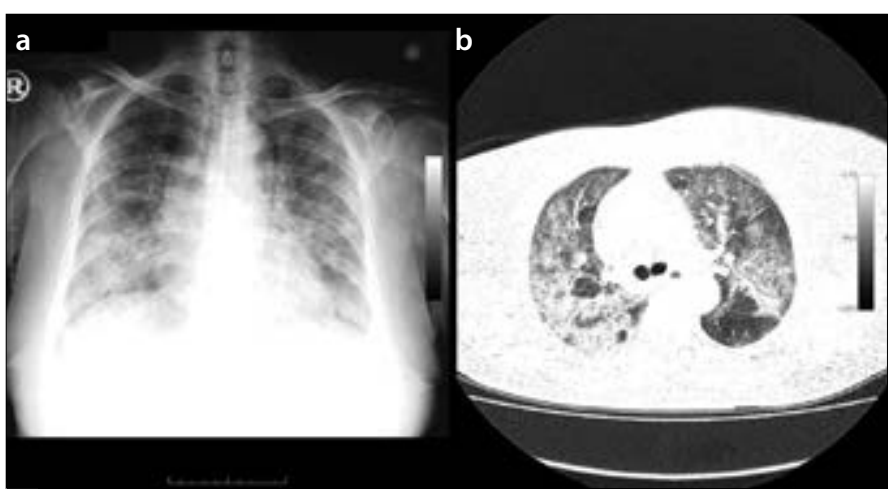

Figure 1. a, b. The presence of a diffuse alveolar pattern in both lungs on chest radiography performed before treatment (a). Pre-treatment HRCT; the presence of diffuse alveolar consolidation in axial section at the level of carina, ground-glass densities, and septal thickenings (b)

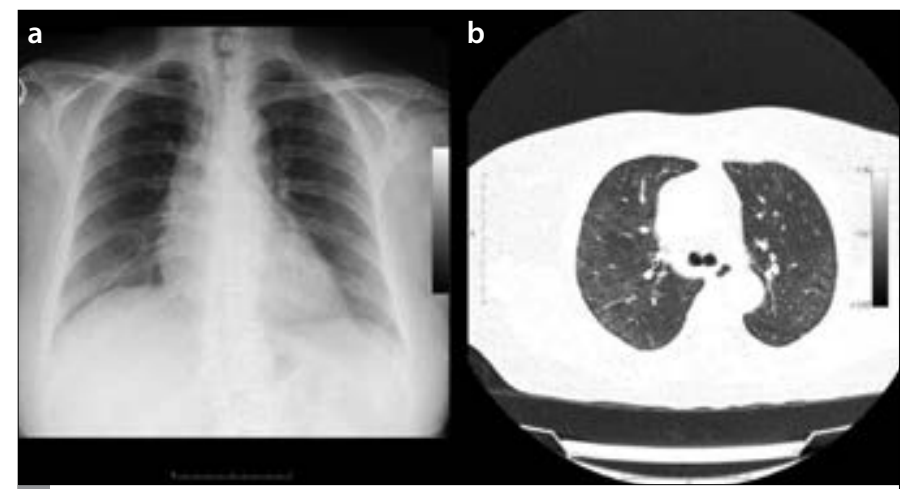

Figure 2. a, b. Post-treatment chest radiography with normal appearance (a). Post-treatment HRCT; the presence of apparent improvement in an alveolar and interstitial pattern as well as minimal septal thickening in the peripheral regions (b)

of a pre-diagnosis of pneumonia. Cytomegalovirus (CMV) IgM was detected as negative in the viral serological examination performed by another health center. The patient whose complaints did not improve for a week despite the present treatment and who experienced decreased oxygen saturation was referred to our hospital for further investigation and treatment. When the history of the patient was questioned, it was learned that she had been treated at the hospital intermittently for arthritis attacks and was thus under salazopyrin therapy for about 2 months 7-8 years previously, but she had discontinued the medication because of gastric bleeding. The patient who had received sulfasalazine and methotrexate (MTX) treatments for the following 4-5 years was additionally receiving LEF $(20 \mathrm{mg} /$ day), hydroxychloroquine sulfide, and deflazacort treatments for the previous 5 months and the sulfasalazine treatment was stopped. It was learned from her history that during the RA treatment, she had not experienced any additional respiratory problem. There was no feature in her family history.

In her physical examination, her general condition was moderate; she was conscious, cooperative, and oriented. Her arterial tension was $110 / 70 \mathrm{mmHg}$, respiration rate per minute was $26 / \mathrm{min}$, pulse was $89 / \mathrm{min}$, and body temperature was $38.6^{\circ} \mathrm{C}$ (axillary). She had shortness of breath and exertional dyspnea. The rate of oxygen satu- ration was $89 \%$. In the bilateral middle zones of both lungs, common crepitant rates were recognized through listening. Secondary to RA, ulnar deviation was present in both wrists. Other system examinations were normal.

The laboratory examination results were as follows: white blood cell count: $7560 / \mathrm{uL}$, hemoglobin: $9.4 \mathrm{gr} / \mathrm{dL}$, thrombocyte: $470,000 /$ $\mathrm{UL}$, erythrocyte sedimentation rate: $120 \mathrm{~mm} / \mathrm{h}, \mathrm{C}$-reactive protein: 3 $\mathrm{mg} / \mathrm{L}$, procalcitonin level: $0.065 \mathrm{ng} / \mathrm{mL}, \mathrm{pH}: 7.46, \mathrm{pCO}_{2}: 33.3 \mathrm{mmHg}$, $\mathrm{pO}_{2}: 55.2 \mathrm{mmHg}, \mathrm{HCO}_{3}: 22.6 \mathrm{mmol} / \mathrm{L}, \mathrm{SaO}_{2}: 89 \%$, and rheumatoid factor level: $13.4 \mathrm{IU} / \mathrm{mL}$. The finding of diffuse alveolar infiltration was observed in both lungs on the chest X-ray (Figure 1a). No growth was seen in the blood and sputum samples.

The antibiotic treatment that had been initiated by another health center because of the present findings was continued. The high resolution chest X-ray (HRCT) taken at that center revealed diffuse alveolar consolidation, partly ground-glass appearance, and septal thickening in both lungs (Figure 1b). The patient was consulted to the rheumatology department regarding lung involvement in RA. The present condition of the patient was not evaluated as lung involvement in RA. Because hypoxemia of the patient continued then, bronchoscopic analysis could not be performed. LEF-induced ILD was considered on the basis of the present HRCT findings, no response to the antibiotic treatment, negative CMV serology, and the clinical picture that occurred following the addition of LEF. Antibiotic and LEF treatment were discontinued. MTX treatment was continued and oral methylprednisolone (MP, $60 \mathrm{mg} /$ day) was started. On the $6^{\text {th }}$ day of the treatment, a significant clinical improvement was observed in the patient. Regression in alveolar infiltration was detected on control chest X-ray and HRCT (Figure 2a, b). No additional findings were found during the follow-up examinations of the patient, and her MP dosage was decreased to $40 \mathrm{mg} /$ day. The patient who showed clinical and radiological improvement was discharged to be given $32 \mathrm{mg} /$ day MP on the $11^{\text {th }}$ day of her admission. Her MP treatment was reduced and discontinued at the end of the first month because she did not have any additional complaints during polyclinic controls. The patient was referred to the rheumatology clinic for re-arrangement of the RA treatment. Written informed consent was obtained from the patient.

\section{DISCUSSION}

Leflunomide is an anti-inflammatory medication that displays immunomodulatory activity. It is currently more preferable than MTX because of its reduced side effects during RA treatment $(5,7)$. Since 2003, when it was started to be used, gastrointestinal, hepatic, hematological, dermatological, neurological, and respiratory side effects related to this drug have been reported in the literature. Among them, side effects associated with lung damage is very rare (7).

Leflunomide-induced lung diseases often develop within the first 20 weeks from its first use (2). Among the risk factors for LEF-induced lung involvement, there is LEF usage at the maximal tolerable dosage (100 mg), age, smoking history, body weight ( $<40 \mathrm{~kg})$, male sex, the presence of underlying ILD, genetic predisposition, and a history of MTX treatment $(2,5)$. LEF-induced lung involvement findings can sometimes occur as benign infiltrations in the lungs but sometimes, they can present with shortness of breath with a mortal course. The mortality rate of this disease has been reported to be $0.7 \%$ (7). In the studies conducted, lung findings such as diffuse alveolar hemorrhage, acute eosinophilic pneumonia, ILD, lung abscess, and cryptogenic 
organized pneumonia that develop secondary to LEF usage were reported $(6,8)$. In our country, there is only the case report by Ulusoy et al. (6) on lung abscess developed after LEF usage in a 43-year-old RA patient. In that case report, it was stated that Staphylococcus aureus was generated from the biopsy materials taken from a lung abscess that developed after LEF treatment was added to her treatment for the previous 5 months. This may be related to the factor generated at abscess material or might have developed after the usage of LEF caused lung damage. In this case, it is seen that there was enough time for the development of lung findings after the LEF usage. In our case, in accordance with the literature, the complaints started after about 5 months from the use of LEF and no growth was detected in the culture samples. In our case, the only risk factor, which is stated in the literature, was the use of LEF with MTX simultaneously.

Leflunomide-induced lung disease can occur in situations in which the medication is taken alone or it can develop especially when combined with MTX (7). It is claimed that this condition is related to the use of LEF when no response is obtained to MTX treatment or that the MTX treatment eases the development of LEF-induced lung disease. Thus, for patients with a history of using MTX, it is important to be careful about the development of lung disease during LEF treatment (2). In the study by Chikura et al. (2), in which they investigated for lung disease after the use of LEF in 26 cases, $97 \%$ of the patients had a history of MTX use and $41 \%$ had a history of the use of a combination of MTX with LEF. In addition, in our case, a history of LEF use with MTX was found, which was similar to that reported in the literature with regard to the development of lung disease in patients receiving LEF combined with MTX.

In drug-induced ILD, nonspecific symptoms and findings such as cough, fever, shortness of breath, decreased saturation, and pleural-type chest pain are observed. In these cases, it is important to eliminate the conditions such as congestive heart failure, infection disease, and malignity together with the accompanying radiological findings (1). Among radiological examination techniques, HRCT is the most common imaging technique, with a high diagnostic value. HRCT findings include grouns-glass appearance, bilateral interstitial nodular pattern, alveolar consolidation, and honeycomb appearance (2). In our case, there was diffuse alveolar consolidation, grouns-glass densities, and septal thickenings, which was consistent with the findings reported in the literature. Especially discontinuation of LEF treatment while MTX treatment was going on and fast clinical and radiological regression after steroid therapy were other supportive findings for our diagnosis in our case.

In drug-induced lung disease, especially, in the presence of suppressed cellular immunity, one of the causes of infection in the differential diagnosis is viral pneumonias. The most common factor is CMV pneumonia in these patients (80-90\%). CMV infection can develop as the reactivation of primary or latent infection. Among other viral pneumonia causes, there is influenza A and B, parainfluenza, adenovirus, respiratory syncytial virus, and herpes simplex virus (9). In our case, no growth was observed in the blood and sputum samples. In addition, CMV serology, the most common cause of viral pneumonia for these patients and which was performed in another health center, was found to be negative.

In the treatment of drug-induced lung disease, the first thing to do is to discontinue the drug thought to have caused the disease and to initiate steroid treatment after the elimination of other etiological factors such as infection, autoimmune disease, malignity, and heart failure. Moreover, oral cholestyramine treatment ( $3 \times 8 \mathrm{gr}$ ) is suggested for facilitating its excretion from the body $(10,11)$. In this case report, only oral steroid treatment was used. Because of the rapid clinical and radiological response to oral steroids, cholestyramine treatment was not used.

\section{CONCLUSION}

It should be considered that in the presence of nonspecific clinical findings, including shortness of breath, cough, and fever developing during the use of LEF, interstitial lung disease associated with this drug can develop, the use of MTX with LEF can ease the development of this condition, and this clinical condition can often occur in the first 20 weeks.

Informed Consent: Written informed consent was obtained from who participated in this study.

Peer-review: Externally peer-reviewed.

Author contributions: Concept - A.Gü.; Design - A.Gü., N.K., M.E.; Supervision - A.Gü.; Resource - N.K.; Materials - A.Gü.; Data Collection and/or Processing A.Gö.; Analysis and/or Interpretation - A.Gü., A.Gö.; Literature Search - A.Gö.; Writing - A.Gü.; Critical Reviews - N.K., M.E.

Conflict of Interest: No conflict of interest was declared by the authors.

Financial Disclosure: The authors declared that this study has received no financial support.

\section{REFERENCES}

1. Matsuno O. Drug-induced interstitial lung disease: mechanisms and best diagnostic approaches. Respir Res 2012; 13: 39. [CrossRef]

2. Chikura B, Lane S, Dawson JK. Clinical expression of leflunomide-induced pneumonitis. Rheumatology (Oxford) 2009; 48: 1065-8. [CrossRef]

3. Emery P, Breedveld FC, Lemmel EM, Kaltwasser JP, Dawes PT, Gömör B, et al. A comparison of the efficacy and safety of leflunomide and methotrexate for the treatment of rheumatoid arthritis. Rheumatology (Oxford) 2000; 39: 655-65. [CrossRef]

4. Behrens F, Koehm M, Burkhardt H. Update 2011: leflunomide in rheumatoid arthritis - strengths and weaknesses. Curr Opin Rheumatol 2011; 23: 282-7. [CrossRef]

5. Kelly C. Leflunomide and the lung. Rheumatology (Oxford) 2009; 48: 1017-8. [CrossRef]

6. Ulusoy H, Bilgici A, Kuru O, Celenk C. Pulmonary abscess due to leflunomide use in rheumatoid arthritis: a case report. Rheumatol Int 2005; 25 : 139-42. [CrossRef]

7. Carloni A, Piciucchi S, Giannakakis K, Nori G, Zobel BB, Poletti V. Diffuse alveolar hemorrhage after leflunomide therapy in a patient with rheumatoid arthritis. J Thorac Imaging 2008; 23: 57-9. [CrossRef]

8. Sakai F, Noma S, Kurihara Y, Yamada H, Azuma A, Kudoh S, et al. Ichikawa leflunomide-related lung injury in patients with rheumatoid arthritis: imaging features. Mod Rheumatol 2005; 15: 173-9. [CrossRef]

9. Kumbasar ÖÖ, Akçay Ş, Akova M, Azap A, Çelikbaş A, Tabak L, ve ark. Türk Toraks Derneği bağışıklığı baskılanmış erişkinlerde gelişen pnömoni tanı ve tedavi uzlaşı raporu. Türk Toraks Derg 2009; 10: S1-16.

10. Hirabayashi Y, Shimizu H, Kobayashi N, Kudo K. Leflunomide-induced pneumonitis in a patient with rheumatoid arthritis. Intern Med 2006; 45: 689-91. [CrossRef]

11. Wong SP, Chu CM, Kan CH, Tsui HS, Ng WL. Successful treatment of leflunomide-induced acute pneumonitis with cholestyramine wash-out therapy. J Clin Rheumatol 2009; 15: 389-92. [CrossRef] 